\title{
Psicologia e diversidade na produção de conhecimento
}

\author{
Psychology and diversity in knowledge production
}

Psicología y diversidad en la producción de conocimiento

O primeiro número do ano de 2021 publicado pela Revista Polis e Psique apresenta não apenas a diversidade de perspectivas temáticas, metodológicas e teóricas em psicologia (Uziel, Prestelo, Jacó-Vilela, Ewald \& Mancebo, 2003), mas o necessário e insistente

posicionamento das diversas psicologias contra as formas de opressão, normalização e segregação, posicionamento esse que é sustentado por análises consistentes das condições históricas que constituem nosso cotidiano.

Neste número 1 de 2021, além de publicarmos 5 artigos e 1 relato de experiência referente ao número regular, temos a satisfação de tornar público o dossiê da sexta edição do Evento "Temas em Debate", cuja temática foi "O que pode a Psicologia Social no presente?", organizado e promovido pelo Curso de Doutorado do Programa de Pós-Graduação em Psicologia Social e Institucional (PPGPSI) da UFRGS. O Evento deriva da disciplina de Métodos III em que as/os doutorandas/os se organizam coletivamente para escrever artigos acerca de temas comuns que serão debatidos por convidados (professoras/es). Os debates também resultam em artigos e estão publicados neste número.

Luciano Bedin da Costa e Rosane Neves da Silva são os Editores Convidados responsáveis pelos textos do Dossiê e, na Apresentação, indicam-nos a importância do evento, bem como da experiência compartilhada entre doutorandos, doutorandas, professoras e professores. Souza e Szuchman (2021) dão pistas da complexidade da tarefa empreendida com o Evento: "as experiências de sala de aula no presente vêm convocando a um exercício que é crítico mesmo a uma psicologia social que já é contra-hegemônica, bem como às nossas práticas docentes, as quais passamos a nos perguntar se não estariam reproduzindo ainda, em alguma medida, modelos naturalizados".

Iniciamos a apresentação dos artigos das submissões abertas com o texto intitulado Uma Relação Possível entre os Inclassificáveis e a Modernidade Líquida em que Talita Noronha Alves e Juliana Fonsêca de Almeida Gama discutem as relações entre a modernidade e as estruturas psíquicas existentes e reconhecidas pela psicanálise Freud-lacaniana. A 
discussão foi realizada através de revisão bibliográfica das obras de Freud, Lacan, Miller e Bauman.

No artigo Situação De Rua e Abordagem Social: Desafios Operacionais ao SUAS, Willian Maciel Krüger, Clarissa De Antoni e Mateus Augusto Pellens Baldissera problematizam as práticas de trabalho psicossocial dentro do Estágio Profissional de Psicologia em um serviço de abordagem social no município de Porto Alegre, Brasil. Seus resultados alocam alguns aspectos estruturais, socio-históricos e biopolíticos como elementos que interferem na execução ótima dos serviços tipificados pelas políticas públicas, marcando a dissonância entre políticas e suas implementações nos serviços. Importante destacar também os (des)investimentos nas políticas públicas têm produzidos efeitos negativos no cotidiano do trabalho, mostrando-se como um projeto político de desmonte e precarização (Marques, Roberto, Gonçalves \& Bernardes, 2019; Aragão \& Hora, 2019).

Evelyn Cristina de Sousa Penas e Idilva Maria Pires Germano assinam o artigo Para Emagrecer o Preconceito Contra Gordos: Discursos Anti-gordofobia no YouTube. No artigo as autoras analisam os discursos contra a gordofobia veiculados em três vídeos brasileiros publicados no YouTube em 2018 com grande visualização. O objetivo é explorar como plataformas digitais podem dar visibilidade a discursos contra-hegemônicos acerca dos corpos gordos, colaborando na disseminação de informações e estratégias de mobilização e combate às formas de discriminação e preconceito. $\mathrm{O}$ artigo é fundamental não apenas para o âmbito da psicologia, mas para os demais campos do conhecimento uma vez que, se as dinâmicas sociais que incidem sobre os corpos produzem condutas de normalização, também é possível criar formas de resistências às pressões estéticas e preconceituosas com relação aos corpos gordos (Vasconcelos, Sudo \& Sudo, 2004; Mello, 2015).

Valéria Nicolini e Karine Vanessa Perez são as autoras do artigo (In)Tratável: Afetações do Corpo em Obra em uma Unidade de Terapia Intensiva Adulta. Nesse texto as autoras buscam identificar quais as afetações que compõem o corpo dentro de uma Unidade de Terapia Intensiva Adulta de um hospital de ensino do interior do Estado do Rio Grande do Sul, Brasil. O artigo é produto de uma pesquisa qualitativa cartográfica, tendo como procedimento metodológico registros de diário de campo em consonância com o referencial teórico sobre o tema. Os resultados destacam as afetações do corpo em questão, 
caracterizando-se como um lócus latente, uma produção de movimentos em busca de tornar visível o que os olhos insistem em não ver.

Esperidião Barbosa Barbosa Neto em seu texto Texto das Palavras e Texto dos Corpos (Peçasamba) apresenta uma peça teórica (e descrição de uma prática) articulando o corpo à dança, cuja arte é capaz de ressignificação da experiência traumática. O trabalho se compõe de duas partes, o texto das palavras e o texto dos corpos. No primeiro uma peça teórica sobre o corpo e a dança, no outro a prática dançante e o diálogo corporal. Conclui-se que a dança, como arte e objeto de transformação, pode resgatar o sentido perdido pelo sujeito no âmbito individual, coletivo, histórico e sociocultural.

Ariana Campana Rodrigues em seu relato de experiência intitulado Construindo um dispositivo coletivo em oficinas na Saúde Mental apresenta a construção coletiva do dispositivo denominado "Planilha da Vida Ocupacional" para acompanhar e analisar a produção de trabalho de pessoas com transtornos mentais em oficinas de geração de trabalho e renda do Núcleo de Oficinas e Trabalho. A construção do dispositivo deu visibilidade ao cuidado ampliado ao oficineiro, a possibilidade de reflexão sobre o próprio trabalho, a perspectiva interdisciplinar de atuação e o amadurecimento da equipe que, acredita-se, são potentes contribuições para com a Reforma Psiquiátrica brasileira.

Henrique Caetano Nardi - Editor Chefe Neuza Maria de Fátima Guareschi - Editora Gerente Giovana Barbieri Galeano - Editora Assistente

\section{Referências}

Aragão, M. R. S. \& Hora, M. M. C. C. (2019). O desmonte do "SUAS" e os seus impactos na execução da Política de Assistência Social no Brasil. Ideias \& Inovação, 5(2), 123-132. Recuperado de https://periodicos.set.edu.br/ideiaseinovacao/article/view/7917/3567

Marques, C.F., Roberto, N. L. B., Gonçalves, H. S. \& Bernardes, A. G. (2019). O que significa o desmonte? Desmonte do que e para quem? Psicologia: Ciência e Profissão, 39(n. spe 2.), e225552, 6-18. Recuperado de https://www.scielo.br/pdf/pcp/v39nspe2/1982-3703-pcp-39-spe2-e225552.pdf 
Mello, J. A. (2015). O corpo gordo: diálogos poéticos em Elisa Queiroz e Fernanda Magalhães. Dissertação (Mestrado em Artes). Universidade Federal do Espírito Santo, Vitória, ES. de https://repositorio.ufes.br/bitstream/10/1690/1/O\%20corpo\%20gordo\%20di\%C3\%A1log os\%20po\%C3\%A9ticos\%20em\%20Elisa\%20Queiroz $\% 20 \mathrm{e} \% 20$ Fernanda\%20Magalh\%C 3\% A3es.pdf

Vasconcelos, N. A., Sudo, I. \& Sudo, N. (2004). Um peso na alma: o corpo gordo e a mídia. Revista Mal-estar e subjetividade, 4(1), 65-93. Recuperado de http://hp.unifor.br/pdfs_notitia/168.pdf

Urziel, A. P., Prestrelo, E. T., Jacó-Vilela, A. M., Ewald, A. P. \& Mancebo, D. (2003). Da diversidade da Psicologia. Revista Estudos e Pesquisas em Psicologia, 3(2), 1-3. Recuperado de http://www.revispsi.uerj.br/v3n2/artigos/Editorial.pdf 